\title{
Transblepharoplasty brow lift
}

\author{
Adrien E Aiache MD FACS \\ Beverly Hills, California
}

\begin{abstract}
AE Aiache. Transblepharoplasty brow lift. Can J Plast Surg 1997;5(3):166-170. The new concepts of endoscopy have taught plastic surgeons to rely on the frontalis-galea-occipitalis unit for brow elevation through inferior release of the frontalis attachment. After proper elevation of the complex through scalp incisions, the technique consists of re-entering the periosteum from below and releasing it from the orbital rim, thus allowing frontalis muscle retraction to take place without being hindered by the tissue's attachment to the periosteum. Elevation is assured by sutures, screws or skin plication.
\end{abstract}

Key Words: Frontalis-galea-occipitalis complex, Transblepharoplasty brow lift

\section{Élévation du sourcil par transblépharoplastie}

RÉSUMÉ : Les nouveaux concepts d'endoscopie ont enseigné aux plasticiens à se fier à l'unité frontalo-galéa-occipitale pour l'élévation du sourcil par le dégagement inférieur du lien frontal. Après élévation adéquate du complexe au moyen d'incisions du cuir chevelu, la technique consiste en la desinsertion du périoste et en son dégagement du pourtour orbital, ce qui permet la rétraction du muscle frontal qui n'est alors plus freiné par la fixation tissulaire au périoste. L'élévation est assurée par des sutures, des vis ou des plis cutanés.

$\mathrm{O}$ wing to the endoscopic approach to brow lifting, the renovated awareness of the frontalis-galea-occipitalis (FGO) muscle unit concept has modified the understanding of eyebrow positioning and elevation. It is now felt that this muscle unit elevates the brow and that its surgical freeing from the inferior-anterior insertion, associated with freeing of the FGO unit from its skull attachments, results in forehead and eyebrow elevation.

Using these premises, the author is obtaining the same physiological results by liberating the frontalis attachments from an inferior approach using the upper lid blepharoplasty incision.

\section{HISTORY}

The brow lift can be accomplished by diverse techniques. Skin excisions include the coronal incision, the pretrichial incision, the forehead furrow incision and the superior brow incision. On the other hand, the technique developed by attempting to lift the eyebrow from a superior blepharoplasty

Correspondence and reprints: Dr AE Aiache, 9884 Little Santa Monica Boulevard, Suite 102, Beverly Hills, CA 90212, USA. Telephone 310-276-5856, fax 310-286-9471 incision has, in the past, been doomed to failure. Suture suspension has not withstood the test of time, although multiple techniques have been developed (1-4).

Bearing in mind the results obtained by endoscopy, an upper lid incision can now be used based on two factors. The first is on the consideration that a brow lift can be obtained by releasing the periosteum, elevating it and creating a gap between its two edges, in addition to the release of the frontalis muscle allowing further muscle retraction and brow elevation. The second factor taught by endoscopy is the understanding that the FGO complex is a continuous synergistic unit that can be released from the skull with the release of the frontal attachments, thus dragging up the eyebrow with it while the depressors are weakened or excised (orbicularis, procerus and depressor supercilii).

\section{SURGICAL TECHNIQUE}

Patients are studied while upright. The amount of eyebrow elevation needed is recognized, and the eyebrow-pupil distance is measured. Proper measurements are compared in the supine and upright positions. The difference in these measurements represents the approximate elevation required. 


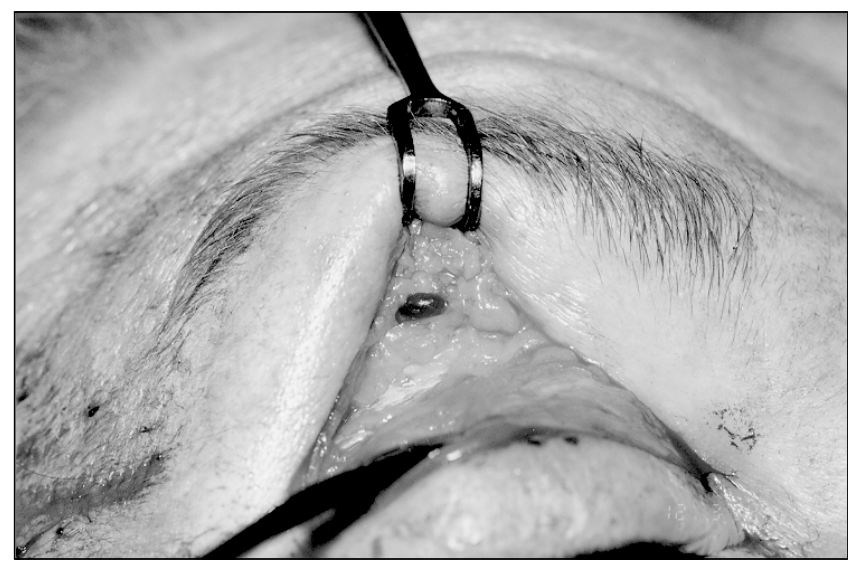

Figure 1) Upper lid blepharoplasty is performed in a routine manner. Visualized are the skin muscle flap retained by a retractor and below it the superior transverse supraorbital vein, and further below, the retroorbicularis ocular fat pads (ROOF)

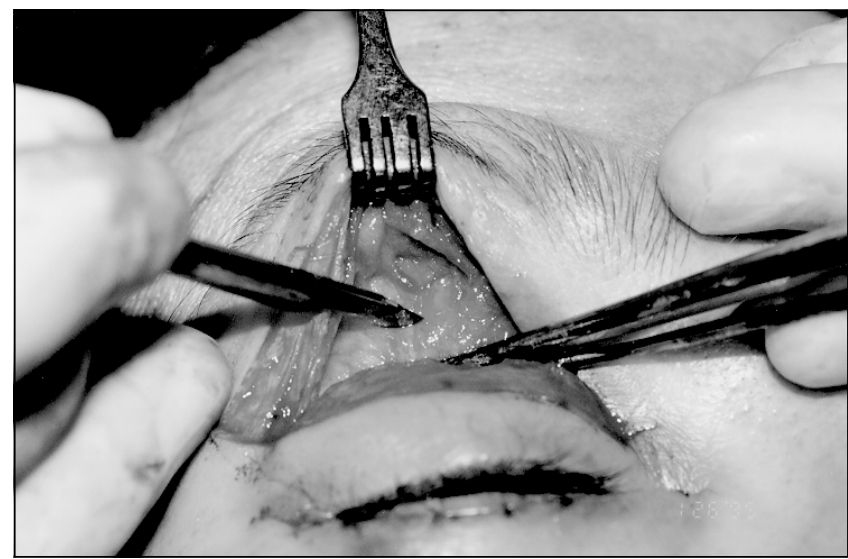

Figure 2) The skin muscle flap is elevated to allow visualization. The scalpel incises through the retro-orbicularis ocular fat pads, and the forceps retain the orbicularis muscle at the level of the orbital rim

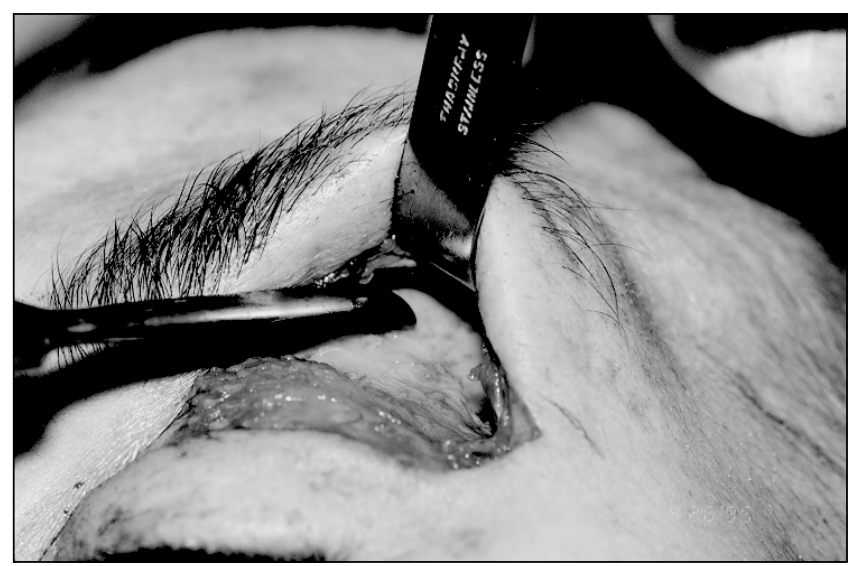

Figure 3) A periosteal elevator is used to free the forehead periosteum with proper protection of the branches of the frontal nerve. This elevation can be performed as high as possible towards the hair implantation and this contributes to the spontaneous elevation of the frontalis muscle insertion

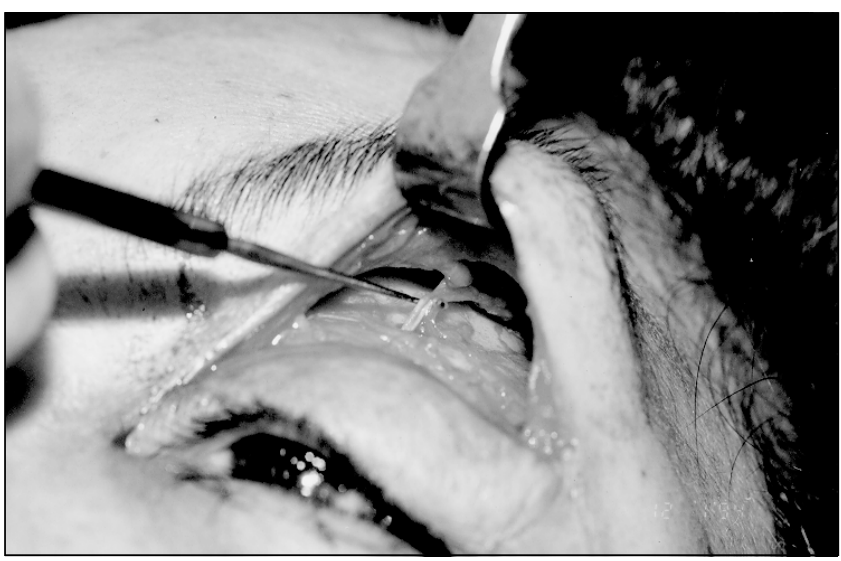

Figure 4) The supraorbital nerve is freed and protected as well as the supratrochlear nerve (not seen here)

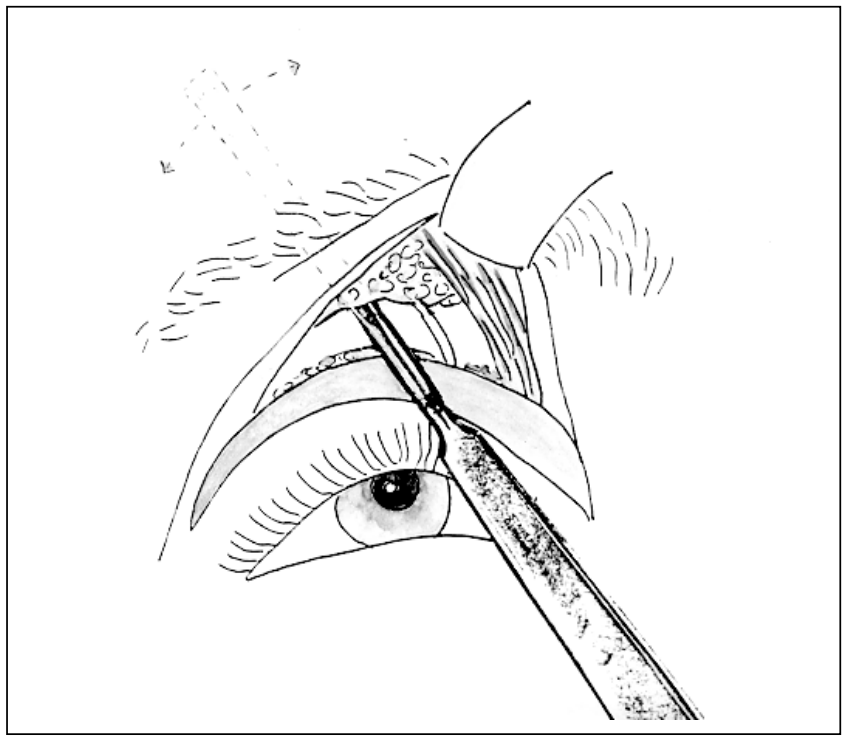

Figure 5) Elevation of the frontal periosteum reaches the hair implantation superiorly. Laterally it reaches the temporal crest, freeing the junction of the temporal crest with the galea where the plane becomes subgaleal under the temporoparietalis fascia and over the deep temporal fascia. The surgeon must stay deep to avoid the facial or temporal nerve branch

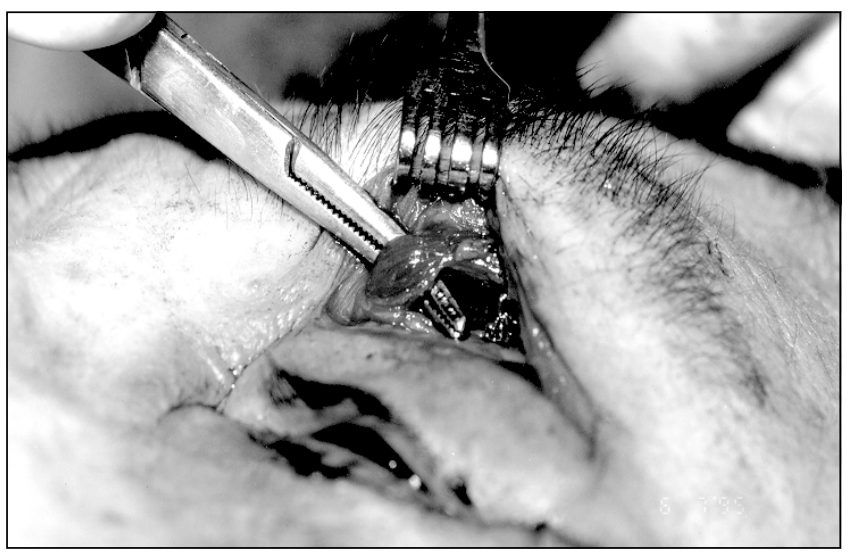

Figure 6) Incision of the periosteum is performed across the radix of the nose towards the opposite border 


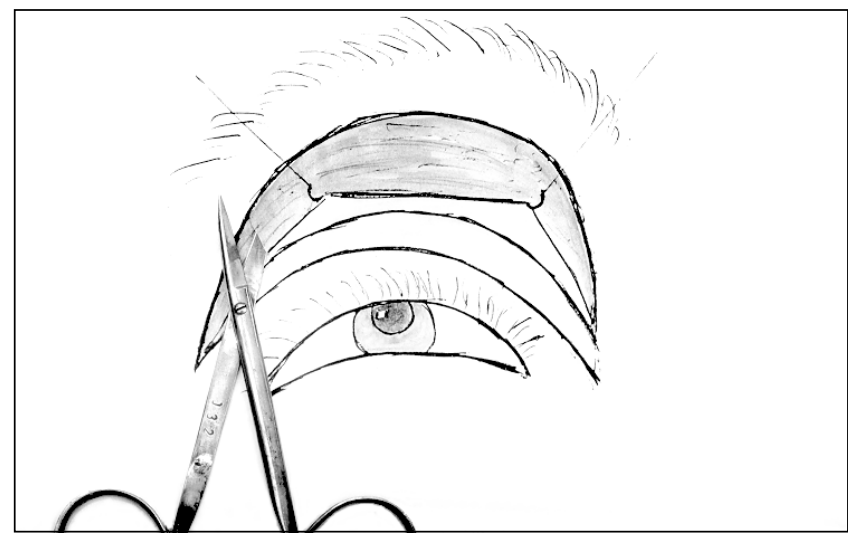

Figure 7) The orbicularis outer belly is weakened by lateral myotomyneurotomy

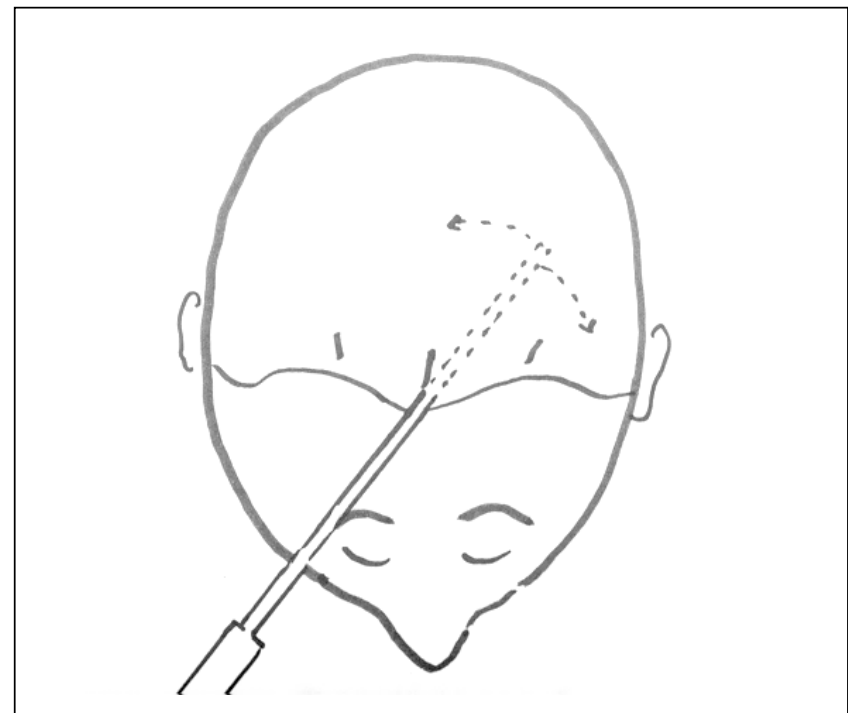

Figure 8) To obtain further elevation of the brows, a superior single median incision behind the hairline is made, elevating the galea posteriorly towards the occipitalis muscle, allowing the frontalis-galea-occipitalis $(F G O)$ unit to contract and retract posteriorly

\section{SURGERY}

Patients are taken to the operating room, and general anesthesia is administered. The upper lid blepharoplasty technique is performed as usual, excising an ellipse of upper lid skin and a concomitant strip of preseptal orbicularis muscle. The orbital septum is incised, and the fat pads are extirpated and excised. A superior skin-muscle flap is then created and elevated with sharp scissors liberating the flap from the retro-orbicularis ocular fat (ROOF) pads situated below it and over the periosteum. The muscle-skin flap is elevated over the orbital rim and approximately $1.5 \mathrm{~cm}$ above it until the transverse marginal arcade vessels is visualized. These vessels are constant and define the higher upper level of skin-muscle flap elevation for an eventual ROOF excision (Figure 1).

An incision is made in the periosteum either through or under the ROOF (Figure 2). After incising it horizontally 2 to $3 \mathrm{~mm}$ above the orbital rim, the periosteum is elevated up to the hair implantation in the forehead (Figures 3-5). Elevation is done laterally towards the temporal crest to release the con-

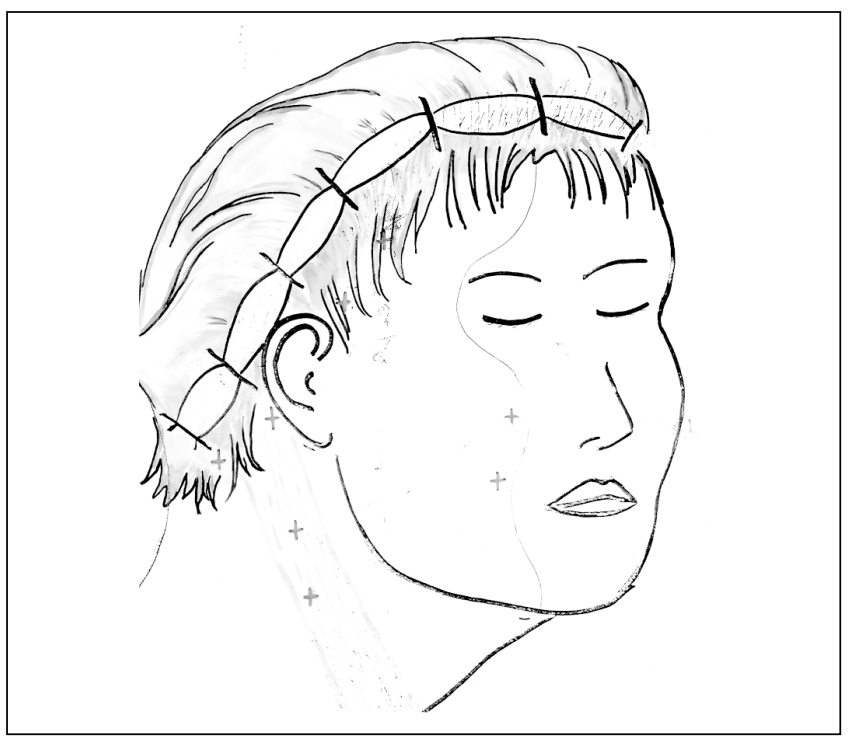

Figure 9) In cases of extreme difficulty in raising the eyebrows and in cases where a skin reduction is necessary, the skin is excised transversely or perpendicular incisions are made through the skin, allowing a folding of that skin and thus creating a crown of skin behind the hairline

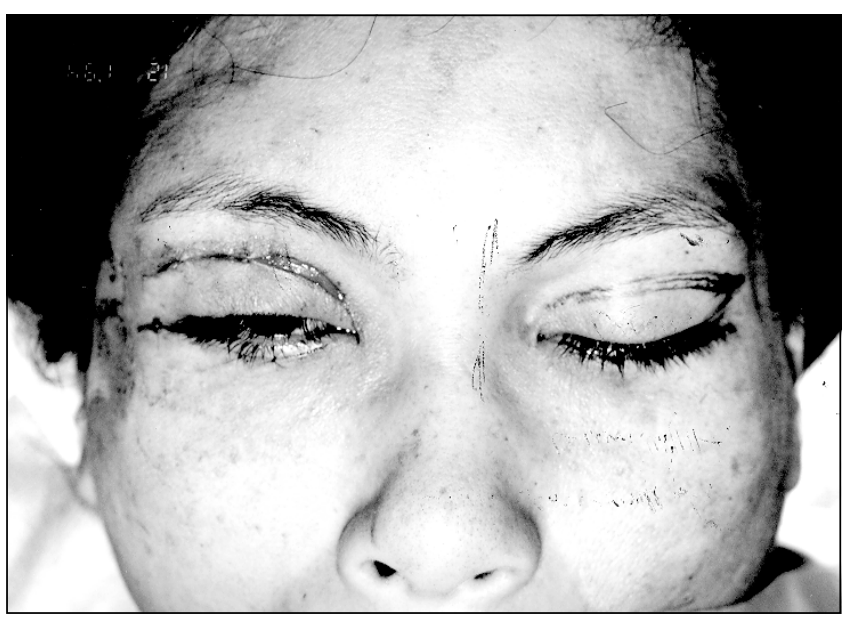

Figure 10) Example of right brow elevation before undertaking the procedure on the left side

joint tendon or orbital ligaments of Knize, and medially after careful dissection around the supraorbital and supratrochlear nerves. In some instances the supraorbital nerve comes up through an upper orbital rim groove and ascends through the frontalis muscle towards the skin. Periosteal elevation is done below it. In some cases, and more often on the right side, the supraorbital nerve extrudes through a supraorbital foramen $5 \mathrm{~mm}$ up to $1.5 \mathrm{~cm}$ over the orbital rim. In other cases, the supraorbital and supratrochlear nerve are only one unit of the frontal nerve, and they exit more medially at the level of the supraorbital rim from a groove. Once the elevation is done medially and laterally, the eyebrow will ascend spontaneously. Medial elevation of the skin orbicularis muscle flap exposes the corrugator muscle (Figure 6), the procerus muscle and, laterally, the orbicularis muscle outer fibres. These fibres are incised or excised in order to weaken the de- 

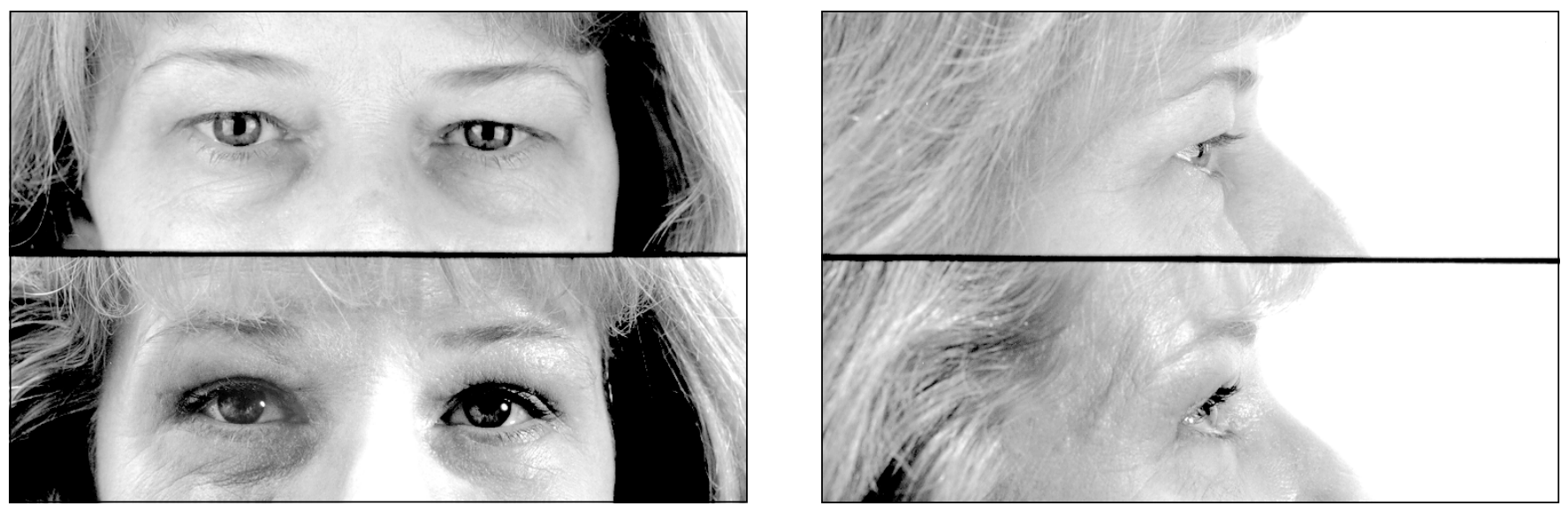

Figure 11) Top left Fifty-year-old woman with brow ptosis; Bottom left Postoperative result through an upper lid brow lift; Top right Lateral view of the patient before and after (bottom right) surgery
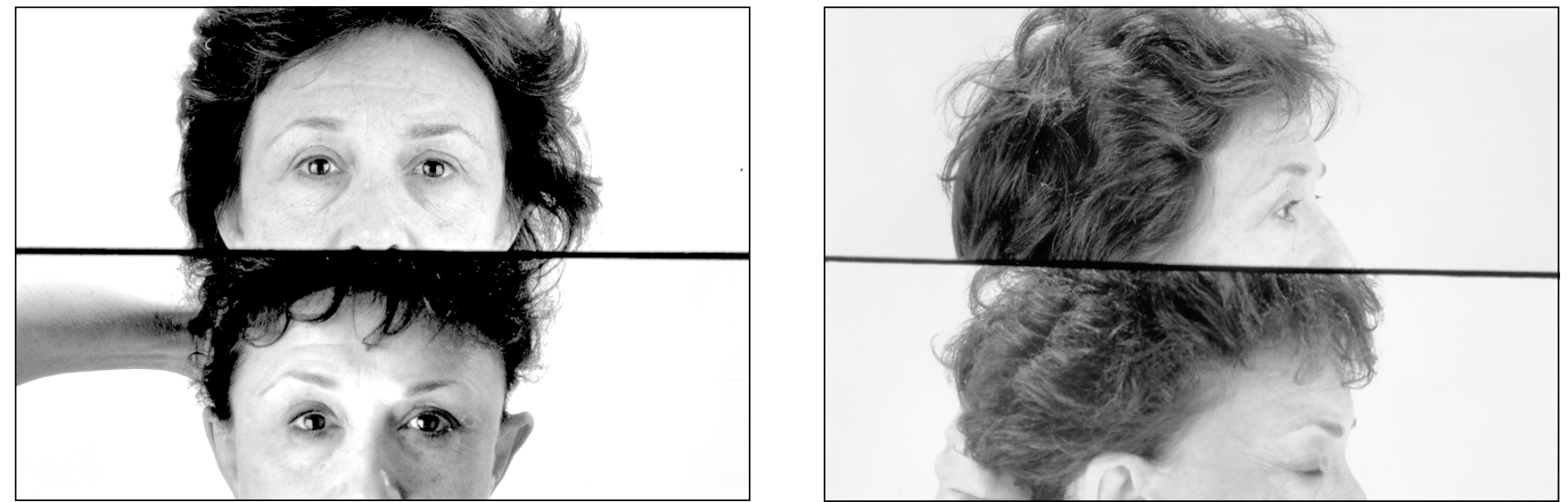

Figure 12) Top left Fifty-six-year-old woman with bilateral brow ptosis and ageing; Bottom left Postoperative result through an upper lid brow lift; Top right Lateral view of the patient before and after (bottom right) surgery
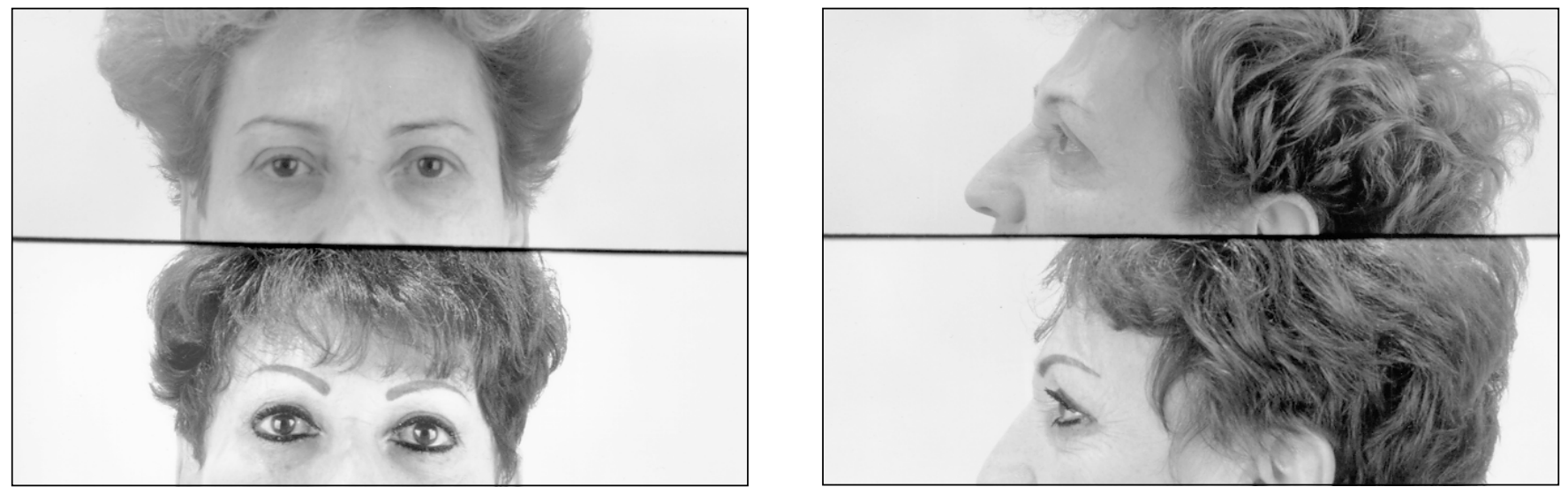

Figure 13) Top left Sixty-three-year-old woman with brow ptosis and facial skin redundancy; Bottom left Postoperative result through an upper lid brow lift; Top right Lateral view of the patient before and after (bottom right) surgery

pressor action of the orbicularis (Figure 7). Once a myotomy is performed, this manoeuvre will obtain a selective neurotomy because the nerves travel into the muscle belly. Treatment of the corrugator muscle and the procerus muscle is tailored to each patient - excising, avulsing or incising these muscles to create a selected neurotomy. If the supraorbital fullness remains exaggerated laterally, a complete excision of the ROOF is performed. After complete elevation of the periosteum is done laterally, this elevation reaches the temporal crest and the temporalis muscle in the parietal area.

If further brow elevation is needed, a midline $1 \mathrm{~cm}$ incision is made behind the anterior hairy scalp implantation 
through the galea (Figure 8). Subgaleal elevation is completed posteriorly towards the occiput and laterally towards the temporalis muscle, connecting it anteriorly with the subperiosteal plane of elevation and thus allowing complete elevation of the FGO complex for further brow lifting.

If the resulting elevation needs further improvement, vertical incisions are made in the frontal and temporal scalp, allowing a 'crown' closure of the skin galea to and incorporating the excess skin obtained by the forehead elevation by folding the scalp in a zone situated behind the hair implantation and suturing one edge of the vertical incision to the other for the desired crown (Figure 9).

\section{DISCUSSION}

It is understood that these techniques are indicated in brow ptosis in patients unwilling to have scalp or forehead incisions. These indications are reserved mainly to brow ptosis in men with baldness and in asymmetry of the brow. Contraindications include high foreheads and lack of upper lid skin in secondary cases which could affect lid closure. This method of brow lifting is based on premises learned from the endoscopic approach and allows surgeons to obtain results similar to those from endoscopic techniques without using endoscopy. The direct visualization of the brow and the infrabrow area is satisfactory, and allows a safe dissection of the branches of the frontal nerve and a safe excision of the orbicularis muscle, the depressor supercilii muscle, the corrugator and the procerus muscle. The blepharoplasty incision avoids a scalp incision with its intrinsic problems such as alopecia, nerve injury and unsatisfactory healing.

Transblepharoplasty brow lift is a choice given to patients who often are not eager to undergo more extensive surgery for brow lifting while they are having a blepharoplasty. In cases where a superior approach is used, it is an additional technique allowing inferior visual control of the surgical results obtained from above. Transblepharoplasty brow lift should be considered an additional technique in brow and forehead lifting associated with upper blepharoplasty (Figures 10-13).

In the 18 patients operated upon with this technique, the first six were performed without an assisting incision behind the hairline superiorly and showed very little brow elevation. The next 12 cases using these incisions from above had good improvement in brow positioning.

Complications consisted of one temporary frontalis paralysis, and cases of unilateral forehead numbness (which recovered completely within six months) and one hematoma.

\section{REFERENCES}

1. Sokol AB, Sokol TP. Transblepharoplasty brow suspension. Plast Reconstr Surg 1982;69:940-4.

2. Knize DM. Transpalpebral approach to the corrugator supercilii and procerus muscles. Plast Reconstr Surg 1995;95:52-62.

3. Vasconez LO, Core JB, Gamboa B, et al. Endoscopic techniques in coronal brow-lifting. Plast Reconstr Surg 1994;94:788-93.

4. Paul MD. Subperioteal transblepharoplasty forehead-lift. Esthet Plast Surg 1996;20:129-34. 